\title{
The Role of ICT within Small and Medium Enterprises in Gauteng
}

\author{
Lloyd Modimogale ${ }^{1}$ and Jan H. Kroeze ${ }^{2}$ \\ ${ }^{1}$ Department of Informatics, University of Pretoria, Pretoria \\ ${ }^{2}$ School of Information Technology, North-West University (Vaal Triangle Campus), South Africa
}

\begin{abstract}
This article discusses the role of information and communication technology (ICT) within the small and medium enterprise (SME) sector in Gauteng, a province in South Africa. ICT plays a very important role in the current knowledge economy. It is vital for SMEs to participate in this economy in order to compete and thrive in the future. The problem is that SMEs are mainly using traditional tools to stay competitive. They need to take advantage of the power of ICT in order to take on the competition, whether small, big or global. Both the traditional and the ICT tools are very important for the competitiveness of the business. The article follows a qualitative research approach and uses semi-structured questionnaires with open-ended questions as data gathering method. There are a number of reasons why an SME might not implement ICT tools, such as limited funds, lack of knowledge, lack of skilled staff and lack of tools. The article highlights the limitation that SMEs have in using ICT and make recommendations on how to overcome them.
\end{abstract}

Keywords: Information and communication technology (ICT), small and medium enterprise (SME), knowledge economy.

\section{Introduction}

Globalisation and digitalisation have changed the way business is done and competes in the marketplace. Information and communication technology (ICT) is the lifeblood of this change. This change has resulted in a new economy known as the knowledge economy. Knowledge is the most important asset in this economy; knowledge is what we sell and buy. Lucchetti and Sterlacchini (2004) highlight the fact that the high growth rate in the US economy during the 1990s, which saw productivity and employment rise, was due to the early and fast adoption of ICT. ICT is the foundation on which the knowledge economy is based. Galloway and Mochrie (2005) substantiate the findings of Lucchetti and Sterlacchini that proper leverage of ICTs is a driver of economic growth, as does Handzic (2004): "Currently, at the forefront of organisational performance are the organisations which recognised that information, knowledge and their intelligent application are the essential factors of success in the new economy, and take advantage of information technology to

Copyright (C) 2011 Lloyd Modimogale and Jan H. Kroeze. This is an open access article distributed under the Creative Commons Attribution License unported 3.0, which permits unrestricted use, distribution, and reproduction in any medium, provided that original work is properly cited. Contact author: Lloyd Modimogale E-mail: modimoll@endiansys.co.za 
achieve [a] high level of efficiency and effectiveness".

Mutula and Van Brakel (2006) agree that information is an important asset that gives small and medium enterprises (SMEs) a competitive advantage in the new economy. However, they point out that access to information is a problem in developing countries like Botswana and South Africa, due to a lack of ICT infrastructure. Information access plays a critical role in the informed decision-making process, making it easy for SMEs to make good competitive decisions. "The ability of SMEs to survive in an increasingly competitive global environment is largely predicated upon their capacity to leverage information as a resource" (Mutula and Van Brakel, 2006). Therefore, it is important for small and medium enterprises to strategically position ICT within their organisation in such a way that they will maximise its benefits.

This article focuses on the role of ICT within the South African SMEs, looking at how the SMEs are currently using ICT. Firstly, the article investigates the concepts of ICT and SMEs. Secondly, it discusses the adoption perspectives of ICT that have been used by authors on this topic. Thirdly, it explores the status quo in South African SMEs regarding the drivers of ICT. Fourthly, it gives an overview of the empirical research conducted and fifthly it sketches the findings and recommendations.

\section{Literature Review}

\section{Definition of ICT}

Ritchie and Brindley (2005) define ICT as "the array of primarily digital technologies designed to collect, organise, store, process and communicate information within and external to an organisation and, in our case, SMEs". ICT covers technologies like the simple telephone, point-of-sale systems, stand-alone PCs, networked environments, Internet and credit card facilities.
ICT can fulfil a number of business needs such as strategic, operational or marketing needs, or a combination of all of them. The different needs of the business led to the categorization of the use of ICT, and Lucchetti and Sterlacchini (2004) categorise them into the following groupings: general-user, production-integration and market-oriented groups. The general-user group is where the basic technologies are used such as telephone, e-mail and Internet in order to carry out administrative functions of the SME, while the production-integration group is where ICT is tightly coupled with production of goods and functionality of the business. The market-oriented group is where ICT is used to market or communicate with the outside world. Different terms are used to express the grouping of the usage of ICT within an SME, but the above categorisation expresses the general purpose of its use.In order for ICT to be used as a competitive tool, it needs to cut across all the categories as discussed above.

\section{Definition of SME}

There is no one way of defining SME, but generally, authors use the number of the employees as an attempt to define it. Southern and Tilley (2000) define small to medium enterprises (SMEs) as businesses that employ 150 people or fewer and are not a subsidiary of a public limited company. Taylor and Murphy (2004) and Martin and Matlay (2001) agree and acknowledge that each individual SME is different and should be treated as such. This reinforces the "small firm and ICT from the small firm perspective" which advocates the uniqueness of each SME and the purpose of adopting or implementing ICT. One common agreement which these authors have is that SMEs are ownermanaged, implying that the owner greatly influences the business decisions and direction.Authors on the topic of adoption of ICT hold three viewpoints, which are: the technology perspective; a management and organisation of technology perspective; and the small firm and ICT perspective. According to Southern and Tilley (2000), the first two have dominated the field of enquiry. Ritchie 
and Brindley (2005) and Southern and Tilley (2000) agree that the focus has been on the three highlighted perspectives as discussed below.

- Technology perspective. According to Ritchie and Brindley (2005), this perspective examines ICT adoption from a technology point of view. The focus is mainly on technology aspects like the Internet or e-mail technology, without looking at how the business can use this technology to be successful. The focus is thus only on the success of the technology driving the business; no consideration of the SME is made. Success is measured from a technology point of view and is not appraised on the success of the business. This perspective holds dangers for both SMEs and large businesses. There have been reports of failures of ERP and CRM projects within organisations, one of the biggest problems not being the technology but the readiness of the organisation to embrace the technology. There are a number of things that the organisation needs to take into consideration when implementing technology, for instance, the organisational culture should be technology oriented; business processes need to be flexible in order to consider technology; one need to check the availability of IT skills needed for implementing the technology, and so on. Lack of consideration of these factors might cause failures in the adoption process.

- Management and organisation of technology perspective. This view is similar to the one above, but with greater emphasis on the management or organisational aspects according to Southern and Tilley (2000). This view places emphasis on the strategic approach to ICT by SMEs and on the capabilities and structures of the SMEs.

- Small firms and ICT from the small firm perspective. This view focuses on the SMEs and how they use technology as a tool to improve their competitiveness. This perspective takes into consideration the vision of the SME. Many authors on this topic are now starting to emphasise this viewpoint. Ritchie and Brindley (2005) and Southern and Tilley (2000) share this view and agree that this is the next focus area for many research endeavours.

The approach of this article is based on the latter perspective, with a particular focus on the owner-managers and how they factor technology into the strategy of the business in order to help the business to become more competitive. It is also important to understand the characteristics and differentiating factors of SMEs.

The owner-manager is a crucial part of the SME as he/she makes all or most of the decisions regarding the business (Southern and Tilley, 2000; Buckley and Montes, 2002). This view is key for the topic of this article particularly discussing competitive positioning of ICT as a tool for the SME, because it requires strategic influence for the management or owners. However, Martin (2005) points out that the owner-managers have the following limitations:

- Capability gaps or knowledge gaps prevent effective technology use and selection.

- Their intuitive and organic styles of management have important consequences for the way in which they evaluate and use technology.

- The owner-managers' personal skills and mind-sets influence their organisations' culture. This means that if the ownermanager is technology averse it will be difficult to adopt ICT and use it as a tool.

Barriers towards SMEs' adoption of ICT as a competitive tool

There are a number of stumbling blocks or barriers that make it difficult for SMEs to adopt ICT. Ngwenyama and Morawczynski (2007) argue that everyone assumes that ICT will successfully bring about benefits, but not all environments are the same. The issues affecting successful implementation or adoption of ICT are both socio-economic and technological. MacGregor and Vrazalic (2006) agree that the barriers to adopting 
ICT by SMEs are both socio-economic and technological, by pointing out that the barriers can be caused by factors external and/or internal to the organisation, which in this case is the SME. According to Herselman (2003), "many of South Africa's rural areas exist below subsistence levels and remain impoverished because they have no access to basic infrastructure essential for economic growth and development".

The following categories of barriers that prevent SMEs from adopting ICT exist:

- Lack of knowledge about the strategic use of ICT (Martin, 2005)

There is a lack of knowledge about the potential benefits of ICT and strategies to support SMEs in achieving their business objectives. SMEs face the challenge that generally they are owner managed and the owner makes all or most of the decisions about the business (strategic direction). Unfortunately the ownermanager's limitations become limitations of the business. This barrier can be classified as a strategic level problem. ICT needs to be considered a key player for the SME in reaching its goals.

- Lack of necessary IT skills-base (Mutula and Van Brakel, 2007)

As already expressed, the owner is the centre of the business, making all or most of the decisions in the small business, so the adoption of ICT by the small business depends on the owner's ICT skills, personality and attitude towards technology. The IT-skills problem forms part of the bigger problem of a shortage of specialists in IT/ICT in Africa. The South African Government has set up organisations (SETAs) to try to increase ICT skills. However, the owner-managers' attitudes towards ICT and its value need to change, and each SME needs expertise to work with. The ideal staff level for an SME that considers ICT to be the core of its business strategy is that of a high user group. "Pervasive use of ICT in the economy depends on well-trained human resources for developing relevant applications, supporting and maintaining systems" (Mutula and Brakel, 2007). If they have a well-trained ICT staff, SMEs are likely to adopt and use ICT as a competitive tool successfully. Martin (2005) highlights his findings that successful Internet adoption depends on different roles of employees and uses combat names to describe them, such as warriors, interpreters, clerks and priests. The main aim for using such names was to make them easy to relate to and to give them the kind of responsibility and respect associated with those roles. This stumbling block to the adoption of ICT can be classified under both the strategic and the organisational and behavioural levels of barriers. Getting the right skills is part of the strategic function of the organisation, since understanding that ICT plays a critical role in the business will help in planning the right budget, creating the right job description and knowing how to interview for ICT skills.

- Perceived high setup cost (cf. Jackson, 2007; Herselman, 2003)

ICT is perceived to be expensive by SMEs so they often do not have a budget for it. ICT solutions are generally associated with millions of rands and stories of ICT solutions are synonymous with running over budget. The other problem with regard to the cost of ICT is that SMEs may invest in unnecessarily big solutions due to sale pitches, hype of specific products or market patterns without considering their real need. Often they could have purchased a less complicated, smaller package or programme to meet their needs, and thus paid less. This would be like a farmer buying a 10 ton truck to deliver $200 \mathrm{~kg}$ of vegetables - it will work, but be inefficient and a waste of money. These are the kind of things that give SMEs the impression that the adoption of ICT is very expensive. There are different types of costs associated with ICT: product/solution, development, connectivity, hardware, software, maintaining workforce and hidden costs such as annual license fees, 
upgrade fees, etc. These costs can be overcome by having the right knowledge and know-how. For example, there are lots of open source software (OSS) programmes available - these are free or low cost ICT tools and solutions written by open source communities. These solutions can be used to support business. In terms of connectivity to the World Wide Web (Internet), the South African Government, like many others, is driving the cost of communication down through bodies such as ICASA. Such bodies are constantly forcing telecommunication companies like Telkom to reduce their rates and make communication affordable to everyone. Mobile operators also offer broadband technologies such as 3G or HSDPA (high speed downlink packet access) at a cheaper rate - these are accessible anywhere in South Africa. An SME with the right knowledge can use OSS solutions in order to run the business: solutions such as Skype (for free calls), Turbo cash (accounting software) and others can be combined to offer a total solution for all the business processes. The perceived high cost of ICT can be classified as a strategic and/or technological barrier. Technology can be expensive or cheap, depending on which technology platforms are chosen. Once more, understanding the role of ICT will make it easier for the business to achieve its goal.

- Ever-changing ICT environment (MacGregor and Vrazalic, 2006)

The ICT environment is ever changing, so constant learning and updating of technologies are needed. Technology is constantly evolving, getting faster, smaller, more powerful, or digital, for example. There are two issues here: on the one hand the SMEs need to monitor the kind of technologies that their clients are using and try to make sure that they are on a par in order to serve them. On the other hand, the SMEs do not need to change every time there is a change in technology; this depends on the focus area of the SMEs. This stumbling block touches on all three categories of barriers and diffusion agents. The ICT strategy of the SME needs to take into consideration that technology changes at a rapid rate, the different technologies need to be monitored as they evolve into the future, and the staff needs to be excited enough to have an interest in the changes as they happen.

- Geographical factors (Ngwenyama and Morawczynski, 2007)

ICT makes it easier to reach remote or rural areas. However, there are other factors to be considered, such as the "FedEx effect" which affects deliveries: for instance, rural areas might not have proper address systems, or there might be no roads. South Africa faces the problem of underdeveloped rural areas and welldeveloped urban areas. Most rural areas lack resources and infrastructure and have no proper address systems. Fixedline connectivity in rural areas is still a huge problem, though the use of cell phones is high. Another major problem is the high rate of illiteracy in the rural areas. On the contrary, the urban areas of South Africa are well connected and the use of technology like the Internet is high. This barrier falls under strategic levels of diffusion agents. Issues such as the "FedEx effect" should be addressed at a strategic level. Taking the time to plan overcoming problems such as lack of roads and addresses will make implementation easier.

\section{ICT Value}

According to Schubert and Leimstoll (2007), there are two schools of thought with regard to the issue of ICT value. The one, known as Porter's theories, says that ICT adds value to SMEs and the other, known as Millar's theories, believes that ICT does not really add any value since it is a commodity, just like electricity, available to everyone. Yet, they agree that competitiveness of an SME depends on the ways in which ICT is used to support business processes. Therefore, having ICT implemented in a business does 
not necessarily give the business any competitive advantage, but having it linked to the business processes and strategy will most likely give a competitive advantage.

In general, it appears that SMEs that employ ICT according to the critical success factors below have a better chance of becoming commercially successful (Taylor and Murphy, 2004). The critical success factors are as follows:

- "owner motivation, experience and management skills;

- expertise in managing growth;

- access to resources (money, technology and people);

- innovation, a competitive advantage and flexibility;

- close contact with customers;

- a focus on profits rather than sales; and

- Strong demand and operating in a growth market".

In order to achieve the above critical success factors, the SMEs need to embark on the following:

- They need to have a clear ICT strategy that will govern the adoption process within that particular SME.

- They need to make sure the ICT strategy is aligned with the business strategy, which means that the ICT strategy should support and achieve business goals.

- The SME should make sure that it employs the right skills (permanent or contracted) and identifies the roles that these skills will play in making sure that the SME is successful in leveraging ICT.

\section{South African SMEs}

South Africa is a developing country going through a growth period and exploiting different technologies. According to the World Wide Worx survey on SMEs, there is a huge advantage to be obtained from the use of emerging ICT technologies, particularly Internet connectivity and mobility. Emerging technologies such as VoIP are taking advantage of the converging markets and changing the landscape of business. South African SMEs should especially explore mobile technologies as a large number of South Africans have cell phones and this is a good platform to deliver services to. Goldstuck of World Wide Worx believes that SMEs that are using emerging technology like VoIP stand to benefit and grow their markets (Jackson, 2007).

Converged networks, where voice and data are merged into one infrastructure, are already available, with Skype being one of the most popular of such applications in use. Businesses are starting to use these tools to communicate with clients and with each other. However, the slow take-up of these technologies is a reason for concern since $90 \%$ of businesses still use the old telephone system (cf. Jacskon, 2007), which does not facilitate the use of advanced ICTs. Concerns might be due to a lack of knowledge, a lack of skills to support OSS solutions and/or risk control.

However, one of the biggest problems in South Africa is the high cost of connectivity and lack of infrastructure. According to Herselman (2003), South Africa has been developed in an uneven manner: the urban areas have the latest modern technologies while the rural areas are underdeveloped with little of the infrastructure, such as electricity and telephone lines, that is needed to thrive in the knowledge economy. This highlights the problem of the growing gap of the digital divide between the developed and the developing countries accordingly (Mutula, 2004). As mentioned above, the South African Government is aware of the need to participate in the global knowledge economy. It has thus mandated Telkom (the local telephone company that is partly owned by government) through ICASA (Independent Communications Authority of South Africa) to meet its target of making South Africa a connected country while reducing the cost of communication. 
Setup of the ICT strategy

SMEs need to define an ICT strategy for the business. This will help the business understand the potential of ICT and outline the processes and methods to be followed during adoption. SMEs need to recognise the impact of ICT on their business and should invest in efforts to take advantage of it. The South African Government is busy with awareness campaigns and has set up nonprofit organisations that should help SMEs obtain the necessary ICT resources and advice.

The owner-manager needs to understand that he/she cannot be everything in the business and needs to employ or outsource the ICT function. Software is becoming a service: a good example is First National Bank, which is providing a payroll solution to its SME clients. For the SME, this leads to a reduction in the costs of developing or acquiring payroll solutions and means that maintenance and upgrading of the solutions are taken care of. SMEs need to spend money and time on getting the relevant advice from ICT experts and consultants in order to set up the ICT strategy, based on the SME's business strategy.

By defining the strategic objective of the SME, the SME can decide which strategic investment to make in ICT. Levy et al. (2001) have found that investment in ICT is successful when it takes one of the following two forms: providing efficiency and savings or enabling added value.

The focus-dominance model, proposed by Levy et al. (2001), may be used to fit appropriate ICT solutions to individual SMEs. It is based on the following dimensions of the SME: strategic focus (cost reduction versus value adding) and customer dominance (where the technology to be used is dictated mainly by the customers). Customer dominance refers to the power of important clients, as many "SMEs are driven primarily by customer needs". The model's four domains - coordination, efficiency, collaboration and innovation - create competitive scenarios. The small business would need to identify the quadrant (domain) into which it falls in the focusdominance model, by determining whether its strategic focus is cost saving or value adding, and then determining whether the customer dominance is high or low. For example, an SME in the efficiency quadrant (where cost saving is important and the customer dominance is high) will only need basic ICTs such as accounting and word processing programs. If it is important to improve customer relations (with a more divergent base of clients), the SME fits into the coordination quadrant (low customer dominance) and will have to maintain a customer database to keep track of the clients' preferences. Since value adding is important in the collaboration quadrant, electronic data interchange and materials requirements planning should be facilitated due to a high customer dominance, while electronic business systems are typical of innovation SMEs (low customer dominance). Once the strategic positioning is done, the focus will be on getting the right tools and technology to achieve the strategy.

\section{Alignment of business strategy with ICT strategy}

Aligning the ICT strategy with the business strategy will ensure that ICT is used to deliver on the SME's objectives. The ICT strategy design should be based upon the business strategy, as the SME should not be driven by technology needs but by business needs. Earlier research on this topic was focused more on the technology perspective and on the management and organisation of technology perspectives, overlooking the small firm's perspective, but now the focus is moving towards the relationship between SMEs and ICT from the small firm's point of view. Authors have begun to take the latter perspective more seriously because they have seen the importance of ICT supporting the business process. 
Identification of adoption roles

Identification of the roles needed for adoption will help the SME understand the skills and knowledge needed to adopt ICT. Martin (2005) highlights his findings that successful Internet adoption depends on different roles of employees. The four main roles are: 1 ) leader of the adoption process (warrior), 2) translator of technology into ordinary language so that everyone understands how to use it (interpreter), 3) administrator of technology seeing to it that the technology runs all the time (clerk), 4) technology specialist who is responsible to make sure that the right technology is used/selected and best practices are implemented (priest). These four roles are not only important in the adoption of Internet use but can be used in the adoption of technology in general. The group of high users of ICT would have all four roles implemented, while the medium user of an ICT group would have some of those roles but not necessarily all of them.

\section{Research Design and Methodology}

The study made use of an interpretive research methodology in order to answer the research question because this approach focuses on the social context of information systems (cf. Oates, 2006). The researchers made use of ten case studies as the research strategy with structured questionnaires and follow-up interviews as data collection methods (cf. Oates, 2006). Since there is no extensive local research on the topic, this approach was the best one for obtaining information from South African contacts. According to the literature, the ownermanager is the main decision maker within SMEs. It was, therefore, important to try and extract the information from him/her through the process of interviewing and interpreting the findings. Although this process does not guarantee that the information will be accurate or unbiased, it was the best way given that most of the knowledge would reside in the ownermanager's head.
Data was collected using interviews based on a questionnaire. The questions were openended questions with the aim of giving respondents the freedom to express their own experiences. The study mainly used qualitative analysis to analyse the data. This method allowed the subjects to share their experiences more freely. Since the sample is very small, the findings cannot be generalised in a statistical manner. However, since this is a qualitative study, the results may still be used in a valid way to suggest problematic areas and possible solutions.

Ten SMEs' owner-managers were interviewed in the Pretoria region. There was no special reason for selecting the Pretoria region, except that it was easier to access SMEs in this area. Purposive sampling was used in order to select SMEs from a variety of industries (cf. Oates, 2006). The owners of each SME were chosen as suitable candidates for the interview/questionnaire in line with the findings of Martin (2005) that the ownermanager makes most of the decisions with regard to the SME, thus they would have a good understanding of issues surrounding the SME.

Modimogale (2008) grouped the data into logical groupings in order to analyse it effectively. The following logical groupings, which also summarise the types of questions included in the interview protocol, were applied in analysing and coming up with the findings:

- Workforce knowledge. The aim was to analyse and understand the workforce employed by the SME and at the same time confirm that the business is an SME.

- Current state of ICT within the SMEs. The aim was to establish the current status of ICT usage within the SMEs, and to establish if basic technologies were used.

- Awareness of ICT. The aim was to establish the levels of awareness of ICT and the knowledge economy by the SME owner (as an important part of the SME).

- Decision-making process with regard to ICT. The aim was to gain an understanding 
of the ICT decision-making process within the SMEs. Who makes decisions? What are the ICT decisions based on? Who maintains the ICT infrastructure? How do SMEs deal with growth, scalability issues and staying current and up to date?

- ICT barriers. The aim was to establish the barriers that prevent SMEs from adopting or implementing ICT in their organisations.

- Current processing of information. The aim was to determine how the SMEs carry out their current processing of transactions.

\section{Findings}

The findings are grouped below according to the logical grouping as discussed above. It is important to highlight once again that this research made use of a qualitative approach in trying to answer the research question. The replies were based on the experiences of the SMEs' owners as they run their businesses.

\section{Workforce knowledge}

All the respondents interviewed have a workforce within the required range as discussed in the definition of SME as defined by Southern and Tilley (2000). The number of employees ranges from four up to seventy. This reflects that respondents were chosen in a balanced manner. The employees of all ten respondents have a minimum qualification of Grade 12 (Matric) and six of them employ people with tertiary education. This could imply that an SME requires some level of literacy. The problem is that six out of the ten respondents indicated that their employees are not computer literate. Only technological SMEs employ IT experts as their main business is technology-based. The others do not have any ICT specialists working for them.

\section{Current state of ICT within the SMEs}

$90 \%$ of the respondents agree that their businesses use some form of IT or ICT technology. This seems almost impossible in light of the above discussion on the high levels of computer illiteracy, but the use of user-friendly tools such as telephone, fax, point of sale (POS) and credit card machines facilitate the use of ICT in these circumstances. $70 \%$ of them view technology as important in their business. The kind of technology in use is mostly telephones and standalone computers for Internet purposes. The majority of the respondents applies general-user and market-oriented products to their businesses. This confirms the concerns regarding the slow take-up of advanced technology referred to above.

\section{Awareness of ICT}

Almost all the respondents have some sense of understanding of IT and what the benefit might be, but not enough. They do not know ICT and how it differs from IT. They find IT/ICT complicated and do not want to try to understand it. In fact, none of them has any idea what the knowledge economy is. They do not have dedicated IT or ICT staff to carry out the ICT-related responsibilities. This highlights Mutula and Van Brakel's (2007) point of the need for highly skilled ICT specialists to make strategic decisions with regard to ICT direction. The majority of the respondents generally use friends and family who know a bit about IT/ICT to help or give advice. Their awareness level is very low.

Decision-making process with regard to ICT All the respondents indicated that they are the main decision makers in their business with regard to all decisions, including ICT. This is in line with Martin's (2005) findings that the owner-manager is everything in the business. However, when they have limitations regarding capability, style and motivation, they go to IT shops to get advice on the matter or they ask friends and family that have knowledge of IT. The danger with this approach is that they rely on sales people who do not have any knowledge of their business to advise them on their ICT decision. The kind of information that the owner-manager gets from this process will not be strategic and in line with the business goals. This reflects the lack of ICT specialists in the SME. Not all the respondents have 
dedicated ICT staff. They get help when there is a problem, generally from friends or family. Only two of the respondents have expert technicians to maintain their technologies. Issues such as building a stable and scalable ICT infrastructure to support business processes and future growth are not considered. Decisions are made randomly there are no frameworks or decision structures for ICT.

\section{Barriers}

The respondents listed different barriers that prevent them from adopting or implementing ICT, ranging from socio-economic issues to technology-related issues: lack of money, power cuts, lack of knowledge, and possibility of fraud, technology intimidation and (perceived) high cost of ICT. The listed barriers are very much in line with the literature, with the addition of power cuts as a new barrier that is probably unique to South Africa (the danger of frequent power failures being a result of intermittent load shedding by the national electricity supplier). Most of the barriers could possibly be overcome by learning more about ICT and by SMEs employing knowledgeable ICT staff.

\section{Current processing of information}

The ten interviewed SMEs use very basic ICT. They do not even keep an electronic database of their clients. Two of the ten capture their transaction details on the computer by using a point-of-sales (POS) terminal, while the other eight use manual methods for capturing their transactions. For example, the restaurant owners interviewed use POS to make the process more efficient and to deal with current levels of business. This POS is almost standard in the restaurant industry. The owners admit that the information collected by the POS is used mainly for accounting purposes and not for data mining. The POS does have standard features that give some analysis, but these are not exploited to their full capacity.

\section{Discussions and Conclusion}

There are two schools of thought when it comes to the value of ICT. One school believes that ICT is a commodity and does not add any competitive advantage to the business or SME, while the other believes that ICT does add value to the business and can give a company a competitive advantage. Both beliefs could be correct, depending from which angle one views them. Indeed, when implemented haphazardly, ICT might not add any value and probably will not lead to any competitive advantage for the business, but when ICT is implemented as part of the business strategy to support the business processes it will probably lead to a competitive advantage. Thus, the manner in which SMEs adopt and implement ICT is important as this will determine whether they will gain competitive advantage or not.

\section{Recommendations}

In summary, the recommendations for SMEs to overcome barriers and improve implementation of ICT in their businesses are as follow:

- SMEs should invest in educating their staff and management about ICT and its benefits (Mutula and Van Brakel, 2006).

The first thing that needs to happen is that SMEs must establish ICT as a functional area, just like the functional areas of finance or human resources. By doing so, they will be recognising ICT as an important function that deserves to be taken seriously. Once that is done, they need to identify fitting roles for this function and establish their specifications, to know what abilities, skills and experience they are looking for when they want to fill the roles. When looking for staff to fill the positions they should make sure that they get people with the right qualifications and experience to do the job.

- They should invest in recruiting or outsourcing knowledgeable ICT specialists (Perry, 2007).

If the problem is that an SME cannot afford someone with the required skills, then it could hire a consultant who can give advice and training. The objective will be to get a consulting company that 
understands both ICT and the business aspect. The recent article on ITWeb by Perry (2007), entitled "SMEs get CIO-oncall", discusses this option. Perry also confirms the need for ICT strategic-level thinking within the SMEs. He highlights random decision making with regards to ICT as a problem that needs to be addressed in order to give SMEs competitive capability.

- They should build a culture that is innovative and favourable to technology (Martin, 2005).

Firstly, the owner-manager needs to become aware of and understand the benefits and the role of ICT within the SME. ICT then needs to be prioritised as a functional area. Once this is done the SME should build an ICT culture within the business, by making the business process more reliant on technology and less on manual processes and by continually exploring all the various and newest technological options with their possible benefits to the SME. Constant communication with staff about what is happening is important to make all employees comfortable with it. The SME should also invest in teaching its staff about technology and encourage employees to use technology and join OSS communities. As recommended by Martin (2005), successful Internet adoption depends on different roles being set out. The SME should thus develop different ICT roles and name them in such a way that everyone can relate to them with ease. The aim is to make technology easy and understandable so that everyone feels comfortable with it and applies it effectively.

- ICT decisions should be informed and based on ICT knowledge (Perry, 2007).

Knowledge is the answer to decision making, therefore the owner-manager needs to be equipped with ICT knowledge or surrounded by knowledgeable ICT people. The SME needs to establish ICT as a function, with ICT represented at the strategic level with input into decisions affecting the future direction of the business. The SME should have a dedicated person or group with the main aim of driving and looking after the technology needs of the SME, with the relevant authority to be able to execute such decisions. The ICT decision makers should include different roles, such as leader of technology (warrior), translator of technology (interpreter), documenter of technology (clerk), and holder of special knowledge (priest). The objective with assigning roles is to make ICT more manageable and less intimidating. It is thus vital to employ ICT staff with experience and knowledge of their work, to ensure that decisions are relevant and suitable to the SME and contribute to its success. The other solution is to use consulting agents to obtain information that can help in decision making. A good example is the "CIO-on-call services" as discussed by Perry's (2007) article that can be used to get expert advice. The challenge is to choose the right consultant with the appropriate technical and business experience, preferably an independent one with no association with any particular products (otherwise he or she might be concerned with making sales and not have the business's interests at heart). It is imperative to have a knowledge transfer plan with the consulting company and to ensure that training of the SME staff is part of the output. Learning is a big part in knowledge management and decision making, with great benefits for the future. This aspect is crucial, especially for SMEs with limited budgets.

Based on the literature review above, the following general steps to using ICT as a competitive tool are suggested:

- Step 1: Set up an ICT strategy based on the business goal and objectives. The focusdominance model referred to above should be used to identify and implement the suitable ICTs based on the strategic focus of the organisation.

- Step 2: Make sure the ICT strategy is aligned with the business strategy. 
- Step 3: Identify the role that ICT will be playing within the SME, using the focusdominance model.

- Step 4: Choose the adoption strategy that is right for a specific business, considering the nature of the business from the "small firm perspective" (Southern and Tilley, 2000).

\section{Future work}

There is still a lot of research needed in this area, especially from a South African point of view. South Africa, like many developing countries, relies on SMEs to reduce unemployment and to contribute toward the growth of the economy. Research into how ICT can enhance SMEs in order to keep them competitive and sustainable in the knowledge economy (information era) is at the top of many governments' agendas around the globe. It is thus important that proper needs analyses be undertaken and solutions be provided that assist SMEs. Other factors, such as the characteristics of SMEs, should be studied in greater detail in order to see how they affect the adoption of ICT by SMEs. Researchers may look at a comparison of SMEs' ICT use in African countries and other developing countries. Various studies may focus on different aspects, for example, commonalities and differences between these countries' adoption of ICT, technological challenges, cultural barriers and opportunities, as well as leadership issues.

\section{References}

Buckley, P. and Montes, S. (2002), Main Street in the Digital Age: How Small and MediumSized Businesses are Using the Tools of the New Economy, U.S. Department of Commerce, Economics and Statistics Administration.

Galloway, L. and Mochrie, R. (2005), 'The Use of ICT in Rural Firms: a Policy-Orientated Literature Review,' Info, 7(3), 2005, 33-46.
Handzic, M. (2004), Knowledge Management: through the Technology Glass, World Scientific Publishing, Singapore (Series on Innovation and Knowledge Management, 2).

Herselman, M. E. (2003), 'ICT in Rural Areas in South Africa: Various Case Studies,' Proceedings of Informing Science, June 2003, 945-955. [Online], [Retrieved September 20, 2009],

http://informingscience.org/proceedings/IS 2003Proceedings/docs/120Herse.pdf

Jackson, D. (2007), 'Convergence: Has it Reached the SME?' Computing SA, July 2007, 10-11.

Levy, M., Powell, P. and Yetton, P. (2001), 'SMEs: Aligning IS and the Strategic Context,' Journal of Information Technology, 16 (3), 133-144.

Lucchetti, R. and Sterlacchini, A. (2004), 'The Adoption of ICT among SMEs: Evidence from an Italian Survey,' Small Business Economics, 23 (2), 151-168.

MacGregor, R. C. and Vrazalic, L. (2006), 'The Effect of Small Business Clusters in Prioritising Barriers to E-commerce Adoption in Regional SMEs,' Journal of New Business Ideas and Trends, 4 (1), 24-44.

Martin, L. (2005), 'Internet Adoption and Use in Small Firms: Internal Processes, Organisational Culture and the Role of the Owner-Manager and Key Staff,' New Technology, Work and Employment, 20 (3), 190-204.

Martin, L. M. and Matlay, H. (2001), '"Blanket" Approaches to Promoting ICT in Small Firms: Some Lessons from the DTI Ladder Adoption Model in the UK,' Internet Research: Electronic Networking Application and Policy, 11(5), 399-410.

Modimogale, L. (2008), ICT and SMEs' Competitiveness in South Africa: How can SMEs Use ICT to Become Competitive in South Africa? M.IT mini-dissertation, 
University of Pretoria. [Online], [Retrieved October 5, 2009],

http://upetd.up.ac.za/thesis/available/etd08272008-111005/

Mutula, S. (2004), 'IT Diffusion in SubSaharan Africa: Implications for Developing and Managing Digital Libraries,' New Library World, 105 (7/8), 281-289.

Mutula, S. and Van Brakel, P. (2006), 'Ereadiness of SMEs in the ICT Sector in Botswana with Respect to Information Access,' The Electronic Library, 24 (3), 402417.

Mutula, S. and Van Brakel, P. (2007), 'ICT Skills Readiness for the Emerging Global Digital Economy among Small Businesses in Developing Countries: Case Study of Botswana,' Library Hi Tech, 25 (2), 231-245.

Ngwenyama, 0. and Morawczynski, 0. (2009), 'Factors Affecting ICT Expansion in Emerging Economies: An Analysis of ICT Infrastructure Expansion in Five Latin American Countries,' Information Technology for Development (Early view). [Online], [Date of preprint used: 20 July 2007], http://www3.interscience.wiley.com/

Oates, B. J. (2006), Researching Information Systems and Computing, Sage, Los Angeles, CA.

Perry, S. (ITWeb features editor) (2007), 'SMEs Get CIO-On-Call,' ITWeb, December 12. [Online], [Retrieved December 22, 2007], http://www.itweb.co.za/sections/business/ 2007/0712121038.asp?S=Consulting\%20an d\%20IT\%20Services\&A=CON\&O=FRGN

Ritchie, B. and Brindley, C. (2005), 'ICT Adoption by SMEs: Implications for Relationships and Management,' New Technology, Work and Employment, 20(3), 205-217.

Schubert, P. and Leimstoll, U. (2007), 'Importance and Use of Information Technology in Small and Medium-Sized
Companies,' Electronic Markets, 17 (1), 3855. [Online], [Retrieved November 23, 2007], http://www.electronicmarkets.org

Southern, A. and Tilley, F. (2000), 'Small Firms and Information and Communication Technologies (ICTs): Toward a Typology of ICTs Usage,' New Technology, Work and Employment, 15(2), 138-154.

Taylor, M. and Murphy, A. (2004), 'SMEs and E-Business,' Journal of Small Business and Enterprise Development, 11 (3), 280-289. 